\title{
Depression, alcohol use disorders and nicotine dependence among patients at a general hospital
}

\section{Depressão, transtornos decorrentes do uso de álcool e dependência de nicotina no hospital geral}

\author{
Neury José Botega, ${ }^{1}$ Gabriela Nero Mitsuushi, ${ }^{1}$ Renata Cruz Soares de Azevedo, ${ }^{1}$ Daniela Dantas Lima, ${ }^{1}$ \\ Priscila Caroline Fanger, ${ }^{1}$ Marisa Lúcia Fabrício Mauro, ${ }^{1}$ Karla Cristina Gaspar, ${ }^{1}$ Viviane Franco da Silva ${ }^{1}$ \\ ${ }^{1}$ Department of Medical Psychology and Psychiatry, Faculdade de Ciências Médicas, Universidade Estadual de Campinas (UNICAMP), \\ Campinas, SP, Brazil
}

\begin{abstract}
Objective: To determine prevalence rates and identify patient characteristics associated with depression, alcohol use disorders and nicotine dependence among individuals admitted to a general teaching hospital. Method: Using the Hospital Anxiety and Depression Scale and Alcohol Use Disorder Identification Test, we assessed 4,352 consecutive medical and surgical patients admitted over a 13-month period. The patients were also asked to report their daily cigarette smoking habits during the last month. Multiple logistic regression analyses were performed, and odds ratios (ORs) were calculated. Results: The mean age of the sample was 49.3 years, and $56.6 \%$ were male. Prevalence rates of depression, alcohol use disorders and nicotine dependence were, respectively, $14 \%, 9.8 \%$ and $16.9 \%$. In the multivariate analysis, depression was associated with previous suicide attempts $(\mathrm{OR}=8.7)$, lower level of education $(\mathrm{OR}=3.6)$, prior use of psychotropic medications (OR = 3.1), cancer $(\mathrm{OR}=1.7)$ and pain $(\mathrm{OR}=1.7)$. Alcohol use disorders were associated with male sex $(\mathrm{OR}=6.3)$, smoking $(\mathrm{OR}=3.5)$, admission for an external cause of injury, such as a traffic accident $(\mathrm{OR}=2.4)$, and previous suicide attempts $(\mathrm{OR}=2.3)$. Nicotine dependence was associated with alcohol use disorders $(\mathrm{OR}=3.4)$, young adulthood $(\mathrm{OR}$ $=2.3$ ), widowhood $(\mathrm{OR}=2.2)$ and previous suicide attempts $(\mathrm{OR}=1.8)$. Conclusion: This is the largest sample of medical and surgical patients ever surveyed with standardized screening instruments in a general hospital in Brazil. The high prevalence rates of psychiatric disorders and the profiles of the patients evaluated in this study underscore the need to develop methods that are more effective for detecting and managing such disorders. Hospital admission should be considered a major opportunity for the detection of psychiatric disorders and the subsequent implementation of the appropriate specific treatment strategies.
\end{abstract}

\section{Resumo}

Objetivo: Identificar taxas de prevalência e perfis de pacientes associados a depressão, transtornos por uso de álcool e dependência de nicotina em individuos internados em um hospital geral universitário. Método: 4.352 pacientes internados consecutivamente foram avaliados pelas escalas Hospital Anxiety and Depression $e$ Alcohol use Disorder Identification Test. Eles também foram questionados sobre uso diário de cigarros ao longo do último mês. Análises de regressão logística múltipla foram realizadas. Resultados: 56,6\% eram de sexo masculino, e a média de idade foi de 49,3 anos. As taxas de prevalência de depressão, transtornos por uso de álcool e dependência de nicotina foram, respectivamente, 14\%, 9,8\% e 16,9\%. Na análise multivariada, depressão associou-se a tentativa prévia de suicídio $(O R=8,7)$, menor escolaridade $(3,6)$, uso prévio de psicofármacos (3,1), câncer $(1,7)$ e dor (1,7). Transtornos por uso de álcool associaram-se a sexo masculino $(O R=6,3)$, tabagismo $(3,5)$, internação por uma causa externa (2,4), notadamente acidentes automobilísticos, e tentativa prévia de suicídio (2,3). A dependência de nicotina associou-se a transtornos por uso de álcool $(O R=3,4)$, idade adulta jovem $(2,3)$, viuvez $(2,2)$ e tentativa prévia de suicídio (1,8). Conclusão: Esta é a maior amostra de pacientes clinicos e cirúrgicos, internados num hospital geral brasileiro, avaliados com instrumentos padronizados. Houve considerável prevalência de transtornos mentais, e os respectivos perfis dos pacientes enfatizam a necessidade de se desenvolver métodos mais eficientes de detecção e de manejo desses transtornos. A internação hospitalar deveria ser tomada como um marco na vida de uma pessoa, a partir do qual se detecta um transtorno psiquiátrico e estratégias especificas de tratamento são implementadas.

Descritores: Depressão; Epidemiologia; Alcoolismo; Tabagismo; Hospital geral

Descriptors: Depression; Epidemiology; Alcoholism; Smoking; General hospital

\section{Introduction}

Psychiatric disorders affect approximately 30\% of patients admitted to medical or surgical wards and are a major cause of morbidity, mortality, low adherence, functional disability and higher health care costs. ${ }^{1-5}$ Early diagnosis and treatment of 
psychiatric comorbidity can have a positive influence on these aspects. ${ }^{6,7}$

Studies conducted in Brazil have reported prevalence rates of psychiatric morbidity among medical and surgical inpatients that vary according to disease category, treatment settings and case-finding procedures. Overall, depressive disorders affect approximately one in every four patients hospitalized in Brazil. ${ }^{1,3,8}$ The current prevalence of alcohol abuse and dependence, including alcohol use disorders (AUDs), ranges from $10 \%$ to $13 \%,{ }^{9-11}$ whereas that of nicotine dependence ranges from $17 \%$ to $21 \% .^{10,12}$

Most studies carried out in general hospital settings in Brazil have involved relatively small patient samples and have therefore identified a limited number of patients with psychiatric disorders, making it difficult to perform multivariate statistical analyses. There is a need for larger studies in order to obtain a more complete picture of patient profiles according to their psychiatric morbidity. The objective of the present study was to determine the prevalence rates of depression, AUDs and nicotine dependence among individuals admitted to a general hospital, as well as to identify the patient characteristics related to those conditions.

\section{Method}

\section{Design and setting}

This was a prospective cross-sectional study based on data collected during the screening phase of the Estudos de Intervenção Breve Oportuna (Brief Opportune Intervention Studies), a series of randomized controlled trials that evaluated brief interventions in depression, AUDs and nicotine dependence in patients admitted to a university hospital. Results of the trials are expected in the near future.

The study was conducted at the Hospital das Clínicas, a public 394-bed teaching hospital affiliated with the Universidade Estadual de Campinas, located in Campinas, Brazil. The hospital is the most highly specialized medical center serving the approximately 5 million people living in the greater metropolitan area of the city of Campinas.

\section{Participants}

During the recruitment period (October 2007 to October 2008), the research team approached 5,357 (85.3\%) of the 6,276 individuals $\geq 18$ years of age who were consecutively admitted to all medical and surgical wards apart from the intensive care unit and psychiatric ward. Failure of the research team to approach all admitted individuals and the rapid departure (short hospital stays) of some patients made it difficult to include all eligible patients. These figures reflect only the first admission of each patient during the recruitment period.

Fifty-nine individuals (1.1\%) declined to participate. The remainder completed a screening questionnaire designed to collect data regarding sociodemographic characteristics, information about current health status and the reason for hospital admission. Of the 5,357 individuals approached, 946 (17.7\%) were excluded, for a variety of reasons: severe clinical conditions that would preclude their being interviewed, including unconsciousness, cognitive impairment and acute physical distress; hospital discharge within the first few hours; place of residence outside the state of São Paulo; and not having a telephone for follow-up contacts. Therefore, the final sample consisted of 4,352 patients.

\section{Instruments}

Data were collected by interview and from patient charts. In addition, we applied the Hospital Anxiety and Depression (HAD) scale and the Alcohol Use Disorder Identification Test (AUDIT). The HAD scale comprises 14 multiple-choice items on anxiety and depression..$^{13}$ Subjects are categorized as suffering from depression if scoring $\geq 8$ (on a scale of 0 to 21 ) on the seven-item depression subscale. This cut-off point corresponds to that previously adopted in a validation study, also carried out in Campinas. ${ }^{8}$ The AUDIT comprises 10 multiple-choice items (maximum score of 40 ) and identifies risk of hazardous and harmful alcohol use, a score $\geq 8$ being indicative of alcohol dependence. ${ }^{14,15}$ Nicotine dependence was assessed by a single question: "Did you smoke on a daily basis during the last month?" Individuals who reported smoking at least one cigarette every day were classified as smokers. Furthermore, lifetime suicidal behavior (lifetime) was assessed by the question "Have you ever attempted suicide?". Moreover, we assessed the severity of pain at the time of the interview using a self-report 10-point scale. Finally, we questioned the patients regarding their religious affiliation and how often they had attended church (or another place of worship) during the last month.

The reason for hospital admission was obtained from the medical records and was coded according to the tenth revision of the International Classification of Diseases (ICD-10). Questionable cases were discussed after a detailed review of the patient chart. We also registered whether the admission was attributable to an external cause of injury (traffic accident, poisoning, gunshot etc.)

The screening interview was conducted within $72 \mathrm{~h}$ after admission, at the patient bedside. Interviewers were assigned to be available on every working day during the recruitment period. Twenty medical students were trained to administer the screening questionnaire. The training consisted of three 2-h modules: an introduction; role-playing interviews; and two interviews with patients under the supervision of the main research team. In order to compensate for illiteracy and low levels of education, all items of the self-report instruments were read aloud by the interviewer. Inter-rater reliability was not assessed.

\section{Data analysis}

For the statistical analysis of the variable occupational status, patients were classified as economically active (employed full-time, part-time or temporarily), economically inactive (unemployed, on leave of absence due to illness or retired) or homemakers. For the statistical analysis of the variable marital status, patients were classified as single, married, divorced or widowed. Other variables were considered dichotomous (e.g., pain: 0 vs. $\geq 1$ ).

Prevalence rates were calculated. Chi-square tests and stepwise multiple logistic regression analyses were used in order to obtain distinct profiles of the three diagnostic groups (depression, AUD and nicotine dependence). Analyses considered each dependent 
variable separately, assessing the patient group with the respective disorder in comparison with all those without (e.g., depressed patients were compared with all other individuals, including patients with nicotine dependence and patients with AUD, who were not depressed). The odds ratios (ORs) were calculated, together with the respective 95\% confidence intervals (95\% CIs). The level of statistical significance was set at $\mathrm{p} \leq 0.05$. The Statistical Analysis System, version 8.02 (SAS Institute, Cary, NC, USA) was used for statistical analyses.

The study design was approved by the local research ethics committee. All participating patients gave written informed consent. Participants were not offered financial assistance or incentives of any kind. Cases of severe mental disorder or suicide risk were reported to the attending physicians.

\section{Results}

Of the 4,352 patients interviewed, $56.6 \%$ were male. The mean age was $49.3 \pm 17.5$ years. The main reasons for admission (by ICD-10 diagnostic group) were as follows: diseases of the digestive system (in 16.3\%); diseases of the circulatory system (in 14.1\%); diseases of the genitourinary system (in 10.9\%); symptoms, signs and abnormal clinical and laboratory findings, not elsewhere classified (in 9.9\%); injury, poisoning and certain other consequences of external causes (in 7.5\%); neoplasm (in $7.5 \%$ ); diseases of the respiratory system (in 6.3\%); and diseases of the musculoskeletal system and connective tissue (in 6.1\%).

The prevalence of depression was 14\% overall (95\% CI: $12.9-15 \%$ ), $10.2 \%$ among males (95\% CI: 9-11.5\%) and 18.8\% among females (95\% CI: 17.1-20.6\%). Depression was associated with previous suicide attempts, low level of education and prior use of psychotropic medications. Depression was found to be more common among females, cancer patients and patients reporting current pain. The prevalence of depression was highest among patients admitted to the oncology, hematology, nephrology and internal medicine wards (32\%, $23.4 \%, 19.4 \%$ and $16.5 \%$, respectively), whereas it was lowest among those admitted to the urology, trauma and orthopedics wards $(7.5 \%$, $9.1 \%$ and $9.4 \%$, respectively).

The prevalence of AUDs was 9.8\% overall, 15\% among males (95\% CI: 13.6-16.5\%) and 2.8\% among females (95\% CI: 2.1 $3.7 \%)$. It is of note that the prevalence of AUDs was highest $(27.1 \%)$ among patients admitted due to external causes of injury (85\% of which were traffic accidents). The prevalence of AUDs was highest among patients admitted to the orthopedics, oncology and trauma wards $(17.3 \%, 15.5 \%$ and $13.5 \%$, respectively), whereas it was lowest among those admitted to the urology, internal medicine and nephrology wards (2.5\%, 5.1\% and 5.9\%, respectively).

The prevalence of nicotine dependence was $16.9 \%$ overall, was 20.7\% among males (95 CI: 19.1-22.3\%), was 12.1\% among females (95\% CI: 10.6-13.6\%), was 2.5 times higher among patients with AUDs than among those without and was quite high among widowed patients (27.6\%). The prevalence of nicotine dependence was highest among patients admitted to the infectious diseases ward, orthopedics ward and semi-intensive care unit (25.9\%, 20.5\%, and $20.3 \%$, respectively), whereas it was lowest rates among those

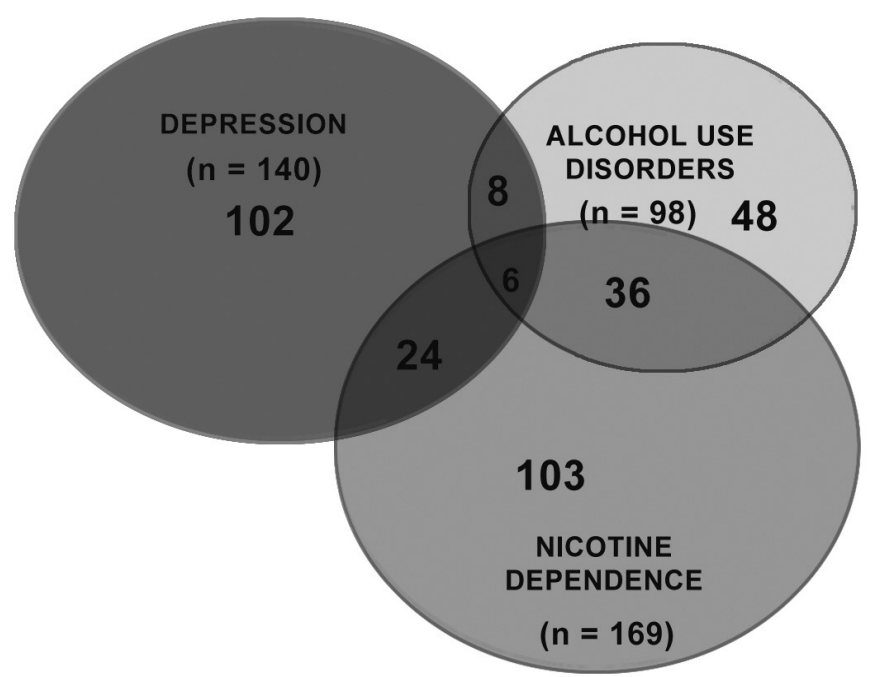

Figure 1 - Overlap among depression, alcohol use disorders and nicotine dependence (per 1,000 inpatients).

admitted to the nephrology, urology and gastrointestinal surgical wards $(8.6 \%, 11.1 \%$, and $12 \%$, respectively).

Some combination of depression, AUD, nicotine dependence and a physical problem was seen in $7.4 \%$ of the patients (Figure 1). Among the patients with AUDs, $42.8 \%$ also had nicotine dependence. There was no statistically significant association between AUD and depression. Of the patients with nicotine dependence, $17.7 \%$ had depression.

The main patient characteristics associated with depression, AUD and nicotine dependence are shown in Table 1 (univariate analyses). Table 2 shows the patient characteristics for which the OR was greater than 1.5 in the multiple logistic regression analysis.

\section{Discussion}

To our knowledge, this is the largest sample of medical and surgical patients ever surveyed by standardized screening instruments in a general hospital in Brazil. Consecutive ward admissions were assessed for 13-month period. Our results showing high prevalence rates of depression, AUDs and nicotine dependence among patients admitted to a general hospital (14\%, $9.8 \%$ and $16.9 \%$, respectively) corroborate those of earlier studies. ${ }^{5,16}$ Two or more of these conditions coexisted in $7.4 \%$ of the cases. The considerable size of the sample (4,352 patients) allowed the prevalence rates, by patient group and hospital ward, to be estimated more accurately, as well as allowing patient profiles to be derived through multiple logistic regression analysis.

Because the reasons for admission were grouped into the broad ICD-10 chapter codes, neither those reasons nor the specific disease groups were employed in the statistical analyses. In addition, we employed no measure of illness severity during the screening phase of the study, since it was considered operationally difficult to obtain a reliable assessment for such a large patient sample. We conducted our study at a public teaching hospital where treatment procedures of high complexity are carried out, and our results therefore cannot be extrapolated to other general hospitals in Brazil. 
Table 1 - Patient characteristics associated with depression, alcohol use disorders and nicotine dependence

\begin{tabular}{|c|c|c|c|c|c|c|c|}
\hline Characteristic & $\mathbf{n}$ & $\begin{array}{c}\text { Depression } \\
\mathrm{n}(\%)\end{array}$ & $\mathbf{p}^{*}$ & $\begin{array}{l}\text { Alcohol use } \\
\text { disorders n (\%) }\end{array}$ & $\mathbf{p}^{*}$ & $\begin{array}{c}\text { Nicotine dependence } \\
\mathrm{n}(\%)\end{array}$ & $\mathbf{p}^{*}$ \\
\hline Total & 4352 & $606(14)$ & & $425(9.8)$ & & $737(16.9)$ & \\
\hline Sex & & & $<0.001$ & & $<0.001$ & & $<0.001$ \\
\hline Male & 2465 & $251(10.2)$ & & $371(15)$ & & $509(20.7)$ & \\
\hline Female & 1887 & $355(18.8)$ & & $54(2.8)$ & & $228(12.1)$ & \\
\hline Age & & & $<0.001$ & & $<0.001$ & & $<0.001$ \\
\hline $18-35$ years & 1094 & $105(9.6)$ & & $156(14.2)$ & & $191(17.4)$ & \\
\hline $36-50$ years & 1132 & $166(14.7)$ & & $147(13)$ & & $256(22.6)$ & \\
\hline $51-62$ years & 1025 & $172(16.8)$ & & $76(7.4)$ & & $180(17.5)$ & \\
\hline$\geq 63$ years & 1101 & $163(14.9)$ & & $46(4.2)$ & & $110(10)$ & \\
\hline Marital status & & & $<0.001$ & & $<0.001$ & & $<0.001$ \\
\hline Single & 865 & $81(9.4)$ & & $125(14.4)$ & & $158(18.2)$ & \\
\hline Married & 2644 & $350(13.2)$ & & $236(8.9)$ & & $416(15.7)$ & \\
\hline Divorced & 415 & $88(21.2)$ & & $16(3.8)$ & & $49(11.8)$ & \\
\hline Widowed & 406 & $87(21.4)$ & & $47(11.5)$ & & $113(27.6)$ & \\
\hline Occupational status & & & $<0.001$ & & $<0.001$ & & $<0.001$ \\
\hline Homemaker & 462 & $86(18.6)$ & & $11(2.4)$ & & $33(12.6)$ & \\
\hline Economically active & 1637 & $164(10)$ & & $250(15.3)$ & & $322(19.7)$ & \\
\hline Economically inactive & 2133 & $344(16.2)$ & & $155(7.2)$ & & $369(17.3)$ & \\
\hline Formal education & & & $<0.001$ & & 0.434 & & 0.007 \\
\hline $0-4$ years & 2012 & $341(17)$ & & $158(7.8)$ & & $308(15.3)$ & \\
\hline$\geq 5$ years & 2306 & $254(11)$ & & $265(11.5)$ & & $424(18.4)$ & \\
\hline $\begin{array}{l}\text { Church attendance in the last } \\
\text { month }\end{array}$ & & & 0.002 & & $<0.001$ & & $<0.001$ \\
\hline 0 times & 1809 & $277(15.3)$ & & $235(12.7)$ & & $379(20.6)$ & \\
\hline$\geq 1$ times & 2196 & $264(12)$ & & $142(6.4)$ & & $272(12.4)$ & \\
\hline $\begin{array}{l}\text { Prior use of psychotropic } \\
\text { medications }\end{array}$ & & & $<0.001$ & & $<0.001$ & & 0.613 \\
\hline Yes & 955 & $277(29)$ & & $57(5.9)$ & & $167(17.5)$ & \\
\hline No & 3373 & $322(9.6)$ & & $366(10.8)$ & & $564(16.7)$ & \\
\hline Previous suicide attempt & & & $<0.001$ & & 0.009 & & $<0.001$ \\
\hline Yes & 240 & $109(45.8)$ & & $35(14.6)$ & & $64(26.6)$ & \\
\hline No & 4097 & $494(12.1)$ & & $387(9.4)$ & & $669(16.3)$ & \\
\hline $\begin{array}{l}\text { Admission due to external } \\
\text { causes of injury** }\end{array}$ & & & $<0.001$ & & 0.007 & & $<0.001$ \\
\hline Yes & 465 & $46(9.9)$ & & $126(27.1)$ & & $129(27.7)$ & \\
\hline No & 3871 & $559(14.5)$ & & $296(7.6)$ & & $605(15.6)$ & \\
\hline Cancer & & & 0.001 & & 0.148 & & 0.033 \\
\hline Yes & 675 & $123(18.3)$ & & $54(8)$ & & $95(15.4)$ & \\
\hline No & 3668 & $483(13.2)$ & & $368(10)$ & & $640(17.4)$ & \\
\hline Pain & & & $<0.001$ & & 0.031 & & 0.163 \\
\hline Yes & 1855 & $326(17.6)$ & & $204(11)$ & & $332(17.9)$ & \\
\hline No & 2460 & $275(11.2)$ & & $221(9)$ & & $397(16.1)$ & \\
\hline
\end{tabular}

${ }^{*}$ chi-square test

** $85 \%$ traffic accidents

Although standard psychiatric interviews are reliable and efficient, they require considerable time and are not readily accessible as standard practice in non-psychiatric settings. The prevalence rates of psychiatric morbidity reported in studies using the DSM-IV criteria and a standard interview are close to, or slightly lower than, the rates reported here, which were obtained by self-report screening instruments. ${ }^{16-19}$ This might be due in part to the fact that we employed instruments with very favorable psychometric properties, as documented in validation studies carried out in Brazil and abroad. ${ }^{8,14,15,20,21}$ However, it should be borne in mind that the CAGE questionnaire might have been preferable to the AUDIT, as suggested in a validation study of the former, involving medical patients at another general hospital in Brazil. ${ }^{22}$

The prevalence rates of depression reported among patients at general hospitals in Brazil—ranging from $26 \%^{3}$ to $59.1 \%{ }^{23}$ vary more than do those of AUD and nicotine dependence in the same setting. These discrepancies among studies are 
Table 2 - Logistic multiple regression analyses for depression, alcohol use disorders and nicotine dependence

\begin{tabular}{lc}
\hline Correlates & OR (95\% CI) \\
\hline Variables associated with depression & \\
Previous suicide attempt & $8.7(6.1-12.4)^{\star * *}$ \\
Less schooling & $3.6(2.1-6.1)^{\star * *}$ \\
Prior use of psychotropic drugs & $3.1(2.5-3.9)^{\star * *}$ \\
Cancer & $1.7(1.3-2.2)^{\star *}$ \\
Pain & $1.7(1.3-2.1)^{\star * *}$ \\
Female sex & $1.6(1.3-2.1)^{\star * *}$ \\
Variables associated with alcohol use & \\
disorders & \\
Male sex & $6.3(4.1-9.6)^{\star * *}$ \\
Smokers & $3.5(2.6-4.6)^{\star * *}$ \\
Admission due to external causes of injury & $2.4(1.7-3.3)^{\star * *}$ \\
Previous suicide attempt & $2.3(1.4-3.7)^{\star *}$ \\
Younger age & $1.9(1.2-3.0)^{*}$ \\
Economically active $x$ inactive & $1.6(1.2-2.1)^{\star *}$ \\
Variables associated with nicotine & \\
dependence & \\
Alcohol use disorders & $3.4(2.6-4.4)^{\star * *}$ \\
Younger age (18-35 years vs. $\geq 63$ years) & $2.3(1.6-3.4)^{\star * *}$ \\
Widowed vs. married & $2.2(1.6-2.9)^{\star * *}$ \\
Previous suicide attempt & $1.8(1.2-2.6)^{\star *}$ \\
No church attendance in the last month & $1.7(1.4-2.1)^{\star * *}$ \\
Male sex & $1.6(1.3-2.0)^{* * *}$ \\
\hline
\end{tabular}

${ }^{*} p<0.01 ;{ }^{* *} p<0.001 ;{ }^{* * *} p<0.0001$

primarily attributable to differences in terms of the settings, the samples surveyed, the methodological instruments employed (ranging from just a few questions to standardized screenings and psychiatric interviews) and the definitions adopted (ranging from depressive adjustment disorder to major depression). At a university hospital in Porto Alegre, Brazil, the use of the Primary Care Evaluation of Mental Disorders and the Beck Depression Inventory resulted in prevalence rates of depression of $34.6 \%$ and $20.1 \%$, respectively. ${ }^{24}$

The prevalence rate of depression obtained in the present study $(14 \%)$ was lower than that reported in most studies conducted in Brazil, as well as being lower than the $29.2 \%$ prevalence rate of major depression obtained in a study conducted at the same institution and employing the Mini-International Neuropsychiatric Interview (MINI) to assess a random sample of 253 patients. ${ }^{11}$ We find this intriguing, since a comprehensive review found the $\mathrm{HAD}$ scale to perform well in assessing depressive symptom severity and caseness for depression in medical and psychiatric inpatients, as well as in primary care patients and in the general population. ${ }^{20}$ The higher figure using the MINI might be due in part to overscoring of patient complaints on the part of the medical students who conducted the interviews. It is also possible that, in the present study, we included fewer cases of depression because we more often approached patients within the first $24 \mathrm{~h}$ after admission, thereby including a higher number of less severe cases that would be discharged soon afterwards.

It has been demonstrated that a significant proportion of patients presenting with major depressive disorder during the early part of their stay at a general hospital will show persistent and severe depression at discharge and over several months of followup. ${ }^{4,6,25}$ Despite extensive efforts made over the years to increase the rate of detection of depression in non-psychiatric settings, it seems that there has been little improvement over time. Although the use of screening and case-finding instruments to improve the quality of care for depression has been largely supported, we cannot assume that such measures will improve the ability of non-specialists to recognize and manage depression. Previous systematic research in this area has produced conflicting results. ${ }^{18}$

Nicotine dependence was determined by a single question. This operational choice was based on the criterion adopted by previous studies ${ }^{26,27}$ and on the controversial findings ${ }^{28}$ regarding the psychometric properties of the Fagerström Test for Nicotine Dependence (FTND), which is the instrument most widely used for assessing the severity of nicotine dependence. In the present study, the prevalence of nicotine dependence was $16.9 \%$, equal to the rate of current smoking reported for a random sample of 111 patients admitted to a large public hospital in the city of São Paulo. The authors of that study applied the FTND and measured exhaled carbon monoxide, considering a level $>6 \mathrm{ppm}$ to be a significant indicator of recent smoking. ${ }^{12}$ The prevalence of nicotine dependence found in our study is also similar to the $21 \%$ obtained in a study that administered the FTND to inpatients at a public teaching hospital in the same city. ${ }^{10}$ These rates are considerably higher than the $10.1 \%$ observed in a large community study conducted in several Brazilian cities, ${ }^{29}$ indicating that smoking is overrepresented among patients admitted to non-psychiatric wards of public hospitals. In our sample, the demographic characteristics positively associated with smoking were similar to those reported in the community: young adulthood, male sex and widowhood. ${ }^{29}$ The proportion of smokers among patients admitted to the infectious diseases ward, orthopedics ward and semi-intensive care unit was twice the hospital-wide average. This finding indicates the need for further studies, as well as for the implementation of smoking cessation strategies. The higher frequency of previous suicide attempts among the smokers evaluated in the present study is in line with the fact that current smoking has been reliably associated with suicide, in case-control and cohort studies. ${ }^{30}$ The most plausible but relatively untested explanation for that association is that smokers have pre-existing conditions that increase their risk for suicide.

The prevalence of AUDs in our study $(9.8 \%)$ is lower than the prevalence of alcohol dependence derived from a survey conducted in large Brazilian cities (12.3\%). ${ }^{29}$ Nevertheless it is above the $8.4 \%$ estimated in a community survey of a cluster sample of 515 individuals living in the urban area of the city of Campinas, in which the AUDIT was also used. ${ }^{31}$ The overall prevalence of AUDs in our study does not differ greatly from those obtained in two previous studies: $9.2 \%$ in a study carried out in 2007 at the same hospital, using the MINI $;{ }^{11}$ and $12.3 \%$ in a study carried out in the year 2000 at another university hospital. ${ }^{10}$ The prevalence 
of AUDs was quite high among certain subgroups of inpatients evaluated in the present study. Among those admitted for external causes of injury (mainly traffic accidents), the prevalence of AUDs $(27.1 \%)$ was more than double the average for all inpatients. As in the cases of depression and nicotine dependence, it is of note that the prevalence rates of AUD varied considerably among the hospital wards (above 15\% for the orthopedics and oncology wards, compared with $2.5 \%$ for the urology ward). These distinct prevalence rates and the factors associated with AUDs, as well as the differences between medical and surgical inpatients in terms of the patterns of consumption, should be taken into account in the development of strategies for detecting and treating alcoholrelated diseases.

Despite the high prevalence rates, one to two thirds of all inpatients suffering from a psychiatric disorder go undiagnosed and are therefore not appropriately treated by the medical staff. $3,5,17,18$ Medical and surgical teams working in hospital settings are mainly concerned with solving specific_-often acute-somatic problems. In addition, some patients are reluctant to discuss their emotional responses. As a rule, members of the medical staff fail to acknowledge the causal role of alcohol misuse and smoking in the alcohol-related and tobacco-related diseases they are treating. A typical situation is that of the alcohol-dependent patient admitted as the victim of a traffic accident. After having received emergency and intensive care, such a patient will be probably discharged without a referral to a specialist mental health service. Indeed, this is the type of patient who could benefit most from early detection and therapeutic intervention. In addition, the medical team might consider depressive symptoms to be appropriate ("understandable") to a given situation, thus failing to diagnose and start treatment for depression. High prevalence rates and low rates of detection of psychiatric morbidities are accompanied by a third, complicating, condition: the short hospital stays of most inpatients does not allow time for the treatment of those identified as having a psychiatric disorder.

Our findings highlight the need to develop more effective methods for detecting and managing psychiatric disordersespecially depression, AUDs and nicotine dependence-among patients admitted to general hospitals. Hospital admission should be considered a major opportunity for the detection of psychiatric disorders and the subsequent implementation of the appropriate specific treatment strategies that extend beyond the period of the hospital stay.

\section{Acknowledgements}

This study was funded by the Fundação de Amparo à Pesquisa do Estado de São Paulo (FAPESP, Foundation for the Support of Research in the State of São Paulo; grant no. 06/61885-6).

\section{Disclosures}

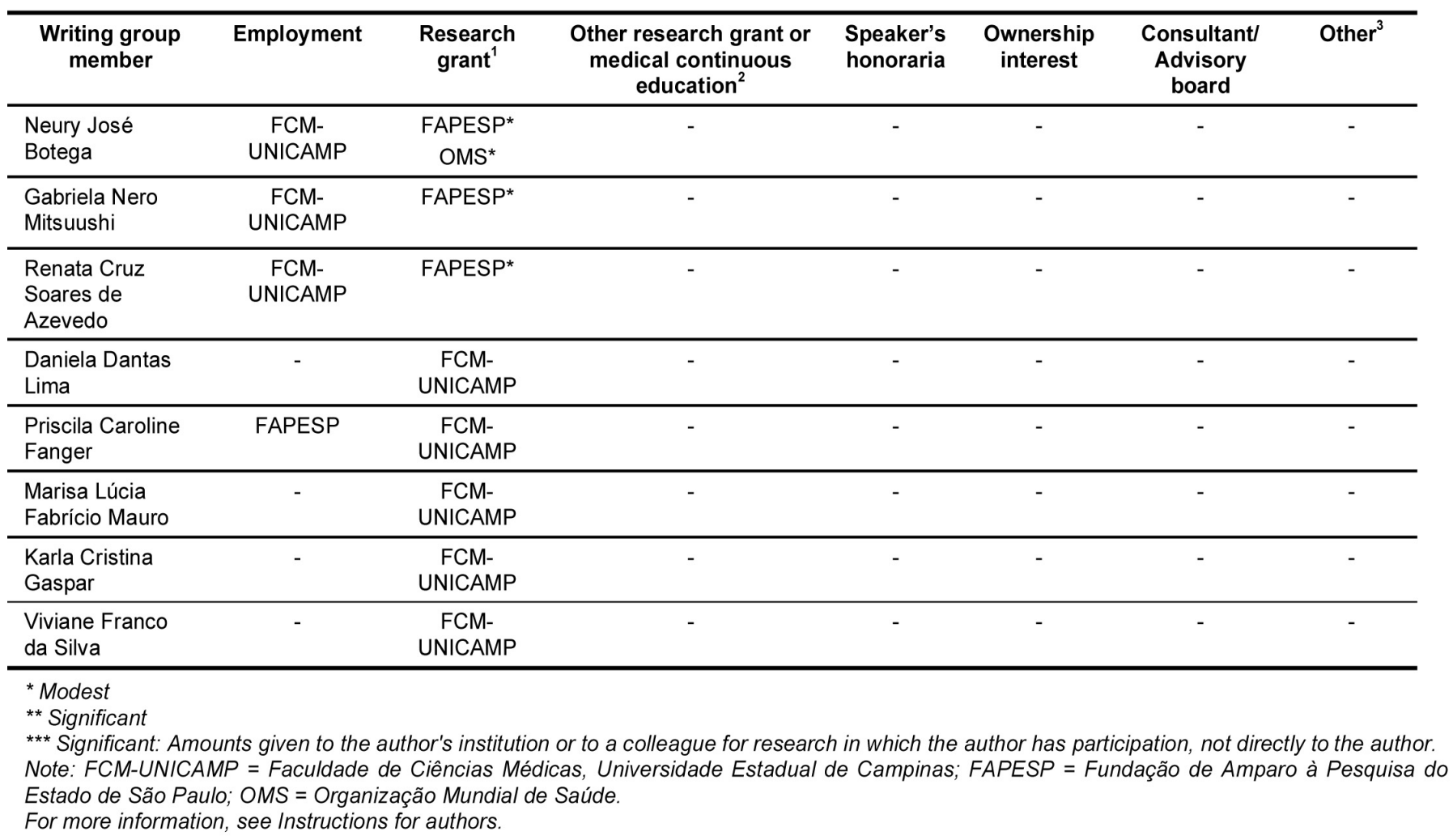




\section{References}

1. Furlanetto LM, von Ammon Cavanaugh S, Bueno JR, Creech SD, Powell LH. Association between depressive symptoms and mortality in medical inpatients. Psychosomatics. 2000;41(5):426-32.

2. Kouimtsidis C, Reynolds M, Hunt M, Lind J, Beckett J, Drummond C, Ghodse H. Substance use in the general hospital. Addict Behav. 2003;28(3):483-99.

3. Cigognini MA, Furlanetto LM. Diagnosis and pharmacological treatment of depressive disorders in a general hospital. Rev Bras Psiquiatr. 2006;28(2):97-103.

4. Egede LE. Major depression in individuals with chronic medical disorders: prevalence, correlates and association with health resource utilization, lost productivity and functional disability. Gen Hosp Psychiatry. 2007;29(5):409-16.

5. Botega NJ, editor. Prática psiquiátrica no hospital geral: interconsulta e emergência. 2a ed. Porto Alegre: Artmed; 2006.

6. McCusker J, Cole M, Ciamp A, Latimer E, Windholz S, Belzile E. Major depression in older medical inpatients predicts poor physical and mental health status over 12 months. Gen Hosp Psychiatry. 2007;29(4):340-8.

7. Strong V, Waters R, Hibberd C, Murray G, Wall L, Walker J, McHugh G, Walker A, Sharpe M. Management of depression for people with cancer (SMaRT oncology 1): a randomised trial. Lancet. 2008;372(9632):40-8

8. Botega NJ, Bio MR, Zomignani MA, Garcia C Jr, Pereira WA. Mood disorders among inpatients in ambulatory and validation of the anxiety and depression scale HAD. Rev Saude Publica. 1995;29(5):355-63.

9. Santos MB, Gailit Junior A, Sato MT, Lawryniuk M, Sater JB, Czpak JC. Aplicação do método CAGE para estudo da prevalência e detecção precoce do alcoolismo em enfermeiras gerais e especializadas de um hospital universitário. Rev Bras Educ Med. 1994;18(1):28-34.

10. Figlie NB, Pillon SC, Dunn J, Laranjeira R. The frequency of smoking and problem drinking among general hospital inpatients in Brazil using the AUDIT and Fagerström questionnaires. São Paulo Med J. 2000;118(5):139-43.

11. Ferreira MH, Colombo ES, Guimarães PS, Soeiro RE, Dalgalarrondo P, Botega NJ. Suicide risk among inpatients at a university general hospital. Rev Bras Psiquiatr. 2007;29(1):51-4.

12. Oliveira MV, Oliveira TR, Pereira CA, Bonfim AV, Leitão Filho FS, Voss LR. Tabagismo em pacientes internados em um hospital geral. J Bras Pneumol. 2008;34(11):936-41.

13. Zigmond AS, Snaith RP. The hospital anxiety and depression scale. Acta Psychiat Scand. 1983;67(6):361-70.

14. Barbor TE, La Fuente JR, Saunders J, Grant M. AUDIT- The alcohol use disorders identification test: guidelines for use in primary care. WHO (PSA/92). 1992;4:1-29.

15. Figlie NB, Pillon SC, Laranjeira RR, Dunn J. AUDIT identifica a necessidade de interconsulta específica para dependentes de álcool no hospital geral? J Bras Psiquiatr. 1997;46:589-93.

16. Mayou R, Hawton K. Psychiatric disorder in the general hospital. Brit J Psychiatry. 1986;149:172-90.

17. Hansen MS, Fink P, Frydenberg M, Oxhoj M, Søndergaard L, Munk-Jorgensen P. Mental disorders among internal medical inpatients: prevalence, detection, and treatment status. J Psychosom Res. 2001;50(4):199-204.

18. Gilbody S, Sheldon T, House A. Screening and case-finding instruments for depression: a meta-analysis. CMAJ. 2008;178(8):997-1003.

19. House A. Mood disorders in the physically ill - problems of definition and measurement. J Psychosom Res. 1988;32(4-5):345-53.

20. Bjelland I, Dahl AA, Haug TT, Neckelmann D. The validity of the hospital anxiety and depression scale - an updated literature review. J Psychosom Res. 2002;52(2):69-77.

21. Lima CT, Freire AC, Silva AP, Teixeira RM, Farrell M, Prince M. Concurrent and construct validity of the AUDIT in an urban Brazilian sample. Alcohol Alcohol. 2005;40(6):584-9.

22. Castells MA, Furlanetto LM. Validity of the CAGE questionnaire for screening alcohol-dependent inpatients on hospital wards. Rev Bras Psiquiatr. 2005;27(1):54-7.

23. Fraguas R Jr, Alves TC. Depression in General Hospital: a study of 136 cases. Rev Assoc Med Bras. 2002;48(3):225-30.

24. Machado SC, Goldim JR, Fleck MP, Eizirik CL. Depression detection in a general university hospital: comparison of data between 1987 and 2002. Rev Gaúcha Enferm. 2003;24(2):209-14.
25. Balestieri M, Bisoffi G, De Francesco M, Eridani B, Martucci M, Tansella M. Six-month and 12-month mental health outcome of medical and surgical patients admitted to general hospital. Psychol Med. 2000;30(2):359-67.

26. Winickoff JP, Tanski SE, McMillen RC, Klein JD, Rigotti NA, Weitzman M. Child health care clinicians' use of medications to help parents quit smoking: a national parent survey. Pediatrics. 2005;115(4):1013-7.

27. Reichert J, Araújo AJ, Gonçalves CM, Godoy I, Chatkin JM, Sales MP, Santos SR; Sociedade Brasileira de Pneumologia e Tisiologia. Smoking cessation guidelines--2008. J Bras Pneumol. 2008;34(10):845-80. Erratum in: J Bras Pneumol. 2008;34(12):1090.

28. Heatherton TF, Kozlowski LT, Frecker RC, Fagerström KO. The Fagerström Test for Nicotine Dependence: a revision of the Fagerström Tolerance Questionnaire. Br J Addict. 1991;86(9):1119-27.

29. Centro Brasileiro de Informação sobre Drogas Psicotrópicas - CEBRID. II Levantamento domiciliar sobre o uso de drogas psicotrópicas no Brasil: estudo envolvendo as 108 maiores cidades do país: 2005. Brasília: Secretaria Nacional Antidrogas / Universidade Federal de São Paulo; 2006.

30. Hughes JR. Smoking and suicide: a brief overview. Drug Alcohol Depend. 2008;98:169-78

31. Barros MB, Botega NJ, Dalgalarrondo P, Marín-León L, de Oliveira HB Prevalence of alcohol abuse and associated factors in a population-based study. Rev Saude Publica. 2007;41(4):502-9. 